\title{
Serum Lipoprotein(a) and Lipid Levels in Patients with Chronic Plaque-Type Psoriasis
}

\author{
Melek Aslan Kayıran', (1) Emine Derviş² \\ ${ }^{1}$ Department of Dermatology, Istanbul Medeniyet University Goztepe Training and Research Hospital, Istanbul, Turkey \\ ${ }^{2}$ Department of Dermatology, Yeniyuzyil University Gaziosmanpasa Hospital, Istanbul, Turkey
}

\begin{abstract}
Introduction: Psoriasis vulgaris (PV) was considered to be a chronic, recurrent skin disease, but it has been accepted as a chronic systemic inflammatory disease in recent years. Lipoprotein(a) $(\mathrm{LP}(\mathrm{a}))$ is a lipoprotein that is synthesized in the liver and has a low-density lipoprotein (LDL)-like molecular structure consisting of phospholipids, cholesterol, and apolipoprotein B-100 derivative. Serum levels of $L p(a)$ are not affected by the amount of lipid incorporated into the diet and lifestyle changes. The aim of this study is to compare blood lipid and Lp(a) levels between the PV patient group and healthy control group and to investigate whether psoriasis creates a predisposition to atherosclerosis.

Methods: Forty-four patients with clinical and/or histopathological diagnosis of chronic plaque-type PV and 48 healthy subjects were included in the study. Serum total cholesterol, triglyceride, high-density lipoprotein (HDL) cholesterol, serum LDL cholesterol, very low-density lipoprotein (VLDL) cholesterol, and serum Lp(a) levels were measured.

Results: Total cholesterol, triglyceride, and HDL, LDL, and VLDL cholesterol levels were not statistically different between the psoriasis and healthy control groups ( $p=0.071, p=0.374, p=0.060, p=0.421$, and $p=0.759$, respectively). $L p$ (a) levels were higher in the psoriasis group than in the healthy control group $(p<0.001)$.

Discussion and Conclusion: According to the results of our study, increased Lp(a) levels in patients with psoriasis may be more likely to induce atherosclerosis than those in the normal population. On the other hand, the identification of the Lp(a) level in patients with psoriasis with cardiovascular diseases may be an appropriate diagnostic tool for the evaluation of atherosclerotic and vasoocclusive pathologies.

Keywords: Atherosclerosis; cholesterol; lipoprotein(a); psoriasis.
\end{abstract}

$\mathrm{P}$ soriasis vulgaris (PV) was thought to be a limited, chronic, and recurrent skin disease in the past, whereas it has been considered as a systemic inflammatory disease in recent years ${ }^{[1]}$. Its most characteristic lesions are often chronic, sharply limited, vivid red, and pearlescent white squamous plaques. However, there are many variations in the morphological configuration, duration, and severity of the disease. The most common form is chronic plaque-type
PV. Its prevalence is reported to be $2 \%$ of the population worldwide, but it varies among regions ${ }^{[2]}$. Myocardial infarction, pulmonary embolism, and cerebrovascular events are more frequently seen in patients with psoriasis ${ }^{[3]}$. In a study, it was found that the incidence of occlusive arterial diseases increased 2.6 fold, and venous occlusive diseases increased 1.6 fold in patients with psoriasis ${ }^{[4]}$ This condition may be related to lipid metabolism disorders that may

Correspondence (İletişim): Melek Aslan Kayıran, M.D. Istanbul Medeniyet Universitesi, Goztepe Egitim ve Arastirma Hastanesi, Deri ve Zuhrevi Hastaliklar Anabilim Dali, Istanbul, Turkey

Phone (Telefon): +90 5325232873 E-mail (E-posta): melekaslan@gmail.com

Submitted Date (Başvuru Tarihi): 06.02.2018 Accepted Date (Kabul Tarihi): 22.07.2018

Copyright 2018 Haydarpaşa Numune Medical Journal

This is an open access article under the CC BY-NC license (http://creativecommons.org/licenses/by-nc/4.0/). 
be seen in psoriasis patients, but in some studies, it has been attributed to the oxidative stress present during the chronic disease process ${ }^{[5]}$.

Atherosclerosis and hypertension, in which activation of the renin-angiotensin system is more prominent, have been observed more frequently in patients with psoriasis than in normal healthy individuals [6], and some studies emphasize the close monitoring of patients with psoriasis in terms of atherosclerotic pathologies ${ }^{[4]}$. Some reports have indicated an increased incidence of metabolic syndrome in patients with PV in recent years ${ }^{[7,8]}$. Metabolic syndrome is consisted of obesity, diabetes mellitus, hypertension, and dyslipidemia that may affect approximately one quarter of the population ${ }^{[9]}$. The coexistence of these conditions increases the risk of atherosclerosis and cardiovascular disease ${ }^{[10]}$.

Lipoprotein (a) ((Lp(a)) is a lipoprotein with a low-density lipoprotein (LDL)-like structure that is composed of phospholipids, cholesterol, and apolipoprotein B-100 derivatives which is synthesized in the liver. Its molecular structure differs from LDL in that it contains an apoprotein $A$ called apolipoprotein $A^{[11]}$. Elevation of $L p(a)$ levels $>15$ $\mathrm{mg} / \mathrm{dl}$ increases the risk of atherosclerotic vascular disease ${ }^{[12]}$. Lp (a) levels are genetically determined at a rate $>90 \% 13$ and are not affected by the amount of dietary lipid and lifestyle changes.

The aim of the present study was to compare serum lipid and $L p(a)$ levels between the patient group with PV and healthy group and to investigate whether psoriasis creates a predisposition to atherosclerosis.

\section{Materials and Methods}

After obtaining permission for the study, 44 patients with clinical and/or histopathological diagnosis of chronic plaque-type PV constituted the patient group while 48 control subjects without any disease comprised the control group. Exclusion criteria for the PV group were, previously diagnosed hyperlipidemia who are currently on antihyperlipidemic medications; patients with systemic diseases that may affect lipid metabolism (diabetes mellitus, hypertension, hyperthyroidism, hypothyroidism, nephrotic syndrome, and obesity) with a history of hyperlipidemia; patients who administer medications that may interfere with lipid metabolism and pregnancy.

Serum total cholesterol, triglyceride, high-density lipoprotein (HDL) cholesterol, LDL cholesterol, very low-density lipoprotein (VLDL) cholesterol, and serum total cholesterol levels were measured from blood samples drawn from the antecubital veins of patients and control subjects into Vacutainer ${ }^{\circledast}$ blood collection tubes from 8:00 am to 10:00 am. Data were analyzed using the NCSS statistical program version 8.0 for Windows (NCSS Statistical Software, Kaysville, UT, USA). Differences between the groups were compared using chi-square test and Student's $t$ test. A $p$ value $<0.05$ was considered to be statistically significant.

\section{Results}

Of the 44 patients in the psoriasis group, 28 (63.6\%) were female, and $16(36.4 \%)$ were male. The mean age of the patients was $43.2 \pm 19.09$ years. The control group consisted of a total of 48 cases with a mean age of $45.25 \pm 15.45$ years (women: $n=23,47.9 \%$ and men: $n=25,52.1 \%$ ). There was no difference between the study subjects and the control group in terms of gender and age of the participants $(p=0.263$ and $p=0.603$, respectively. $12(27.2 \%)$ of the patients were currently diagnosed while $32(72.8 \%)$ of them were previously diagnosed with chronic plaque psoriasis. 21 (65\%) of the previously diagnosed patients were on topical medications. None of the patients were on systemic treatment regimen for psoriasis.

Increased $L p$ (a) levels were found in 24 patients (54.5\%) along with increased total cholesterol levels in 20 patients (45.4\%), increased LDL levels in 20 patients (45.4\%), increased VLDL levels in 10 patients $(22.7 \%)$, increased triglyceride levels in 3 patients (6.8\%) and decreased HDL levels in 4 patients (9\%) in the psoriasis group.

Increased Lp (a) levels were found in 8 subjects (16.6\%) along with increased total cholesterol levels in 11 subjects (22.9\%), increased LDL levels in 13 subjects $(27.08 \%)$, increased VLDL levels in 6 subjects (12.5\%), increased triglyceride levels in 6 subjects (12.5\%) and decreased HDL levels in 10 subjects $(20.8 \%)$ in the control group (Table 1 ).

There was no statistically significant difference in total cholesterol, triglyceride, and HDL, LDL, and VLDL cholesterol levels between the patient and control groups $(p=0.071, p=0.374, p=0.060, p=0.421$, and $p=0.759$, respectively). Serum $L p(a)$ levels were significantly higher in the patient group $(p<0.001)$ (Table 1).

\section{Discussion}

Atherosclerotic cardiovascular diseases are more frequently seen in PV ${ }^{[14-16]}$. McDonald et al. ${ }^{[4]}$ have shown that patients with psoriasis are predisposed to atherosclerotic cardiovascular diseases and thromboembolic events. This condition may be associated with disorders in lipid metabolism, and its possible relationship with oxidative stress in 
Table 1. Mean $( \pm S D)$ values of the patient and the control groups

\begin{tabular}{lcccccc}
\hline & \multicolumn{2}{c}{ Patient group } & & \multicolumn{2}{c}{ Control group } \\
\cline { 2 - 3 } & $\begin{array}{l}\text { Median serum } \\
\text { level (mg/dl) }\end{array}$ & $\begin{array}{c}\text { Standard } \\
\text { deviation }\end{array}$ & & $\begin{array}{c}\text { Median serum } \\
\text { level (mg/dl) }\end{array}$ & $\begin{array}{c}\text { Standard } \\
\text { deviation }\end{array}$ & $\mathbf{p}$ \\
\hline Total cholesterolemia $112-200 \mathrm{mg} / \mathrm{dl}$ & 184.7 & 5.36 & & 188.62 & 5.69 & 0.071 \\
Triglyceride $50-200 \mathrm{mg} / \mathrm{dl}$ & 122 & 11.42 & & 139.62 & 15.64 & 0.374 \\
$\mathrm{HDL}>35 \mathrm{mg} / \mathrm{dl}$ & 50.7 & 1.89 & & 46.36 & 1.68 & 0.060 \\
$\mathrm{LDL}<130 \mathrm{mg} / \mathrm{dl}$ & 110.63 & 5.32 & & 121.18 & 5.21 & 0.421 \\
$\mathrm{VLDL}<30 \mathrm{mg} / \mathrm{dl}$ & 21.06 & 1.89 & & 21.25 & 1.57 & 0.759 \\
$\mathrm{Lp}($ a) $0-15 \mathrm{mg} / \mathrm{dl}$ & 19.3 & 1.75 & 12.19 & 0.72 & $<0.001$ \\
\hline
\end{tabular}

The units in the first column demonstrate normal serum values. Intergroup difference was calculated using Student's $t$ test.

the chronic disease processes has been suggested in some studies ${ }^{[4]}$. In addition, hypertension, where activation of the renin-angiotensin system plays a prominent role, and atherosclerosis have been more frequently observed in patients with psoriasis ${ }^{[6]}$.

The most important risk factors in the development of atherosclerosis are male gender, history of early onset ischemic heart disease, smoking, hypertension, obesity, sedentary lifestyle, and hyperlipidemia [17].

Among the changes in lipoprotein levels, increases in $L D L$, $V L D L, H D L$, and $L p(a)$ levels are significant for atherosclerosis $[11,12,18]$. Levels of $L p(a)$ are genetically determined in $>90 \%$ of the cases as mentioned before. The levels of $L p(a)$ are not affected by the lipid content of the diet and lifestyle changes ${ }^{[13]}$.

An increase in the incidence of metabolic syndrome in patients with PV has been indicated in recent studies $[7,8$, ${ }^{19]}$. In the meta-analysis performed by Singh et al., ${ }^{[20]}$ concomitancy of these two diseases was reported at a very high rate of $14 \%-40 \%$, and they indicated that as the severity of PV increases, the incidence of metabolic syndrome also increases. Metabolic syndrome is a syndrome in which dyslipidemia, obesity, hypertension, and diabetes mellitus are seen in combination ${ }^{[9]}$. This condition increases the risk of atherosclerosis and cardiovascular disease ${ }^{[10]}$. The relationship between serum lipid levels and psoriasis, which are the most important risk factors for atherosclerosis, has been investigated in light of more frequent observation of occlusive vascular diseases in patients with psoriasis than in the normal population, and conflicting results have been reported.

Serum lipid levels, insulin secretion, and insulin resistance were investigated by Reynoso-von et al., ${ }^{[21]}$ and no significant results were found except for the low levels of HDL. In a similar study Pişkin et al., ${ }^{[22]}$ serum lipids, excluding $L p(a)$, were measured, and only LDL levels were found to be significantly higher in patients with psoriasis.

Kural et al. ${ }^{[5]}$ in 2003 investigated the atherogenic tendency of serum lipids and lipoproteins in patients with psoriasis and its association with the oxidation-antioxidation system. Evidence favoring atherosclerotic tendency was detected in patients with psoriasis including increased levels of atherogenic lipids, lipid peroxidation products, and autoantibodies formed against oxidized LDL and decreased levels of antioxidant enzyme activities and total antioxidant levels. However $\mathrm{Lp}(\mathrm{a})$ levels were not analyzed in that study ${ }^{[5]}$.

One of the interesting studies regarding this issue was

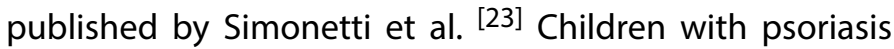
were classified as the patient group and compared with healthy children. Serum total cholesterol levels in children with psoriasis were significantly higher than those in healthy ones. However, Stinson et al. ${ }^{[24]}$ reported that serum cholesterol and $\mathrm{Lp}(\mathrm{a})$ levels in patients with psoriasis are not different from the control group. Seçkin et al. [25] investigated serum lipids and lipoproteins including $L p(a)$ in 32 male patients with psoriasis and reported that serum $L p(a)$ levels are higher in patients with psoriasis than in the control group, but there was no statistically significant intergroup difference.

Similar to our study, Pietrzak et al. ${ }^{[26]}$ found significantly higher Lp(a) levels in patients with psoriasis than in the control group; however, they detected significantly lower HDL levels in the lipid profile of patients with psoriasis relative to the control group contrary to our study. Nevertheless, in contrast to the other studies in which Lp(a) was examined, in our study, serum $L p(a)$ levels in patients with chronic plaque psoriasis were significantly higher than those in the control group. Contrary to other studies related to the subject, there was no statistically significant difference between the other lipid parameters except for $L p(a)$.

According to the results of our study, statistically higher lev- 
els of $L p(a)$ that contribute to the development of atherosclerosis in the psoriasis group relative to the control group apparently support the studies that atherosclerosis is more frequently seen in patients with psoriasis. In this case, measurement of the level of $L p(a)$ in patients with psoriasis who are prone to cardiovascular diseases may be an appropriate diagnostic tool in the evaluation of atherosclerotic and vaso-occlusive pathologies. More accurate results may be obtained by examining this issue in a wider series of cases.

Peer-review: Externally peer-reviewed.

Authorship Contributions: Concept: M.A.K.; Design: M.A.K., E.D.; Data Collection or Processing: M.A.K.; Analysis or Interpretation: M.A.K., E.D.; Literature Search: M.A.K.; Writing: M.A.K., E.D.

Conflict of Interest: None declared.

Financial Disclosure: The authors declared that this study received no financial support.

\section{References}

1. Kalkan G. Comorbidities in psoriasis: The recognition of psoriasis as a systemic disease and current management. Turkderm-Turk Arch Dermatol Venereology 2017;51:71-7. [CrossRef]

2. Parisi $R$, Symmons DP, Griffiths CE, Ashcroft DM; Identification and Management of Psoriasis and Associated ComorbidiTy (IMPACT) project team. Global epidemiology of psoriasis: a systematic review of incidence and prevalence. J Invest Dermatol 2013;133:377-85. [CrossRef]

3. Henseler T, Christophers E. Disease concomitance in psoriasis. J Am Acad Dermatol 1995;32:982-6. [CrossRef]

4. McDonald CJ, Calabresi P. Psoriasis and occlusive vascular disease. Br J Dermatol 1978;99:469-75. [CrossRef]

5. Vanizor Kural B, Orem A, Cimşit G, Yandi YE, Calapoglu M. Evaluation of the atherogenic tendency of lipids and lipoprotein content and their relationships with oxidant-antioxidant system in patients with psoriasis. Clin Chim Acta 2003;328:71-82. [CrossRef]

6. Ena P, Madeddu P, Glorioso N, Cerimele D, Rappelli A. High prevalence of cardiovascular diseases and enhanced activity of the renin-angiotensin system in psoriatic patients. Acta Cardiol 1985;40:199-205.

7. Voiculescu VM, Lupu M, Papagheorghe L, Giurcaneanu C, Micu E. Psoriasis and Metabolic Syndrome-scientific evidence and therapeutic implications. J Med Life 2014;7:468-71.

8. Rodríguez-Zúñiga MJM, García-Perdomo HA. Systematic review and meta-analysis of the association between psoriasis and metabolic syndrome. J Am Acad Dermatol 2017;77:657-66.e8.

9. Eckel RH, Alberti KG, Grundy SM, Zimmet PZ. The metabolic syndrome. Lancet 2010;375:181-3. [CrossRef]

10. Mancia G, Bombelli M, Facchetti R, Casati A, Ronchi I, et al. Im- pact of different definitions of the metabolic syndrome on the prevalence of organ damage, cardiometabolic risk and cardiovascular events. J Hypertens 2010;28:999-1006. [CrossRef]

11. Homma Y. Predictors of atherosclerosis. J Atheroscler Thromb 2004;11:265-70. [CrossRef]

12. Deb A, Caplice NM. Lipoprotein(a): new insights into mechanisms of atherogenesis and thrombosis. Clin Cardiol 2004;27:258-64. [CrossRef]

13. Aasvee K, Kurvinen E, Jordania R, Jauhiainen M, Sundvall J. Lipoprotein parameters in relation to other risk factors of atherosclerosis in adults and newborns: Tallinn Young Family Study. Scand J Clin Lab Invest 2004;64:245-53. [CrossRef]

14. Gottlieb AB, Chao C, Dann F. Psoriasis comorbidities. J Dermatolog Treat 2008;19:5-21. [CrossRef]

15. Choi WJ, Park EJ, Kwon IH, Kim KH, Kim KJ. Association between psoriasis and cardiovascular risk factors in Korean patients. Ann Dermatol 2010;22:300-6. [CrossRef]

16. Di Lisi D, Macaione F, Corrado E, Bonura F, Novo G, Peritore A, et al. Cardiovascular risk profile of patients with psoriasis [Article in Italian]. Recenti Prog Med 2013;104:102-5.

17. Nemati $H$, Khodarahmi R, Rahmani A, Ebrahimi A, Amani M, Eftekhari K. Serum lipid profile in psoriatic patients: correlation between vascular adhesion protein 1 and lipoprotein (a). Cell Biochem Funct 2013;31:36-40. [CrossRef]

18. Koschinsky ML. Lipoprotein(a) and the link between atherosclerosis and thrombosis. Can J Cardiol. 2004;20 Suppl B:3743B.

19. Patel P, Rosen CF, Chandran V, Ye YJ, Gladman DD. Addressing comorbidities in psoriatic disease. Rheumatol Int 2018;38:219-27. [CrossRef]

20. Singh S, Young P, Armstrong AW. Relationship between psoriasis and metabolic syndrome: a systematic review. G Ital Dermatol Venereol 2016;151:663-77.

21. Reynoso-von Drateln C, Martínez-Abundis E, Balcázar-Muñoz BR, Bustos-Saldaña R, González-Ortiz M. Lipid profile, insulin secretion, and insulin sensitivity in psoriasis. J Am Acad Dermatol 2003;48:882-5. [CrossRef]

22. Piskin S, Gurkok F, Ekuklu G, Senol M. Serum lipid levels in psoriasis. Yonsei Med J 2003;44:24-6. [CrossRef]

23. Simonetti O, Ferretti G, Salvi A, Offidani AM, Bossi G. Plasma lipid changes in psoriatic children. Dermatology 1992;185:96-100.

24. Stinson J, O'Toole E, Cooke T, D'Arcy G, Hall M, Barnes L, et al. Cholesterol and lipoprotein (a) levels in psoriasis. Ir Med J 1995;88:128-9.

25. Seçkin D, Tokgözoğlu L, Akkaya S. Are lipoprotein profile and lipoprotein (a) levels altered in men with psoriasis? J Am Acad Dermatol 1994;31:445-9. [CrossRef]

26. Pietrzak A, Kadzielewski J, Janowski K, Roliński J, Krasowska D, Chodorowska $\mathrm{G}$, et al. Lipoprotein (a) in patients with psoriasis: associations with lipid profiles and disease severity. Int J Dermatol 2009;48:379-87. [CrossRef] 